\title{
CORRESPONDENCE
}

\section{Unite to assess contaminant risk}

There is an urgent need for a globally coordinated research programme to evaluate the risks to human health and the environment posed by contaminants of emerging concern, or CECs.

CECs are natural or synthetic chemicals that can affect an organism's ability to communicate with and respond to its environment. Well-known examples of their adverse biological effects include intersex phenotypes in wildlife, and poor sperm quality and quantity in humans (see also R.W. Stahlhut et al. Environ Health Perspect. 115, 876-882; 2007).

Field studies have so far been unsuccessful in predicting CEC effects. This is partly because of the complex interactions and multiple stressors that occur in nature, but also because such investigations often focus on a single chemical or chemical class, or on a specific mechanism or organism, or use environmentally unrealistic experimental exposure levels.

A coordinated programme should integrate new and ongoing research into the sources and fates of CECs, and the exposure risks associated with them. This would replace the present scattershot approach and would provide solutions and reliable information for policy-makers.

Paige J. Novak and 14 co-authors*, University of Minnesota, USA. novak010@umn.edu ${ }^{*} A$ full list of authors is online at http://dx.doi.org/10.1038/471578a.

\section{Funding studies of the unpredictable}

The unpredictability of extreme weather events calls for a mechanism for mobilizing research funds at short notice, so that an event can be investigated while it is still going on.

At the local and national levels, authorities could create a consortium of respected scientists as standby funding recipients. International contributions might be coordinated by a body such as the Intergovernmental Panel on Climate Change, which could set up a worldwide agreement on data and information sharing.

Besides investigations such as model validation, funding bids would need to cover basic research into these extreme weather events. Allocation would have to be decided within days, and research results fed promptly to a United Nations panel.

Such measures could minimize the cost of disastrous weather events over the medium to long term and help to lessen their socioeconomic, cultural and environmental effects.

Brajesh K. Singh University of Western Sydney, Penrith, Australia.b.singh@uws.edu.au

\section{Turkey's research council clarifies role}

Some points you raise about TÜBİTAK, Turkey's scientific and technological research council, need clarification (Nature 470, 436; 2011).

As the main government agency for research management, funding and conduct,

TÜBİTAK aims to create optimal conditions for Turkey's scientific and technological development. It is therefore concerned about the association of several notable scientists with the trial surrounding the Ergenekon organization, which is accused by the Turkish chief prosecutor of plotting against the democratically elected government.

TÜBİTAK has chosen to remain silent out of respect for the principle of judicial independence (as specified in the country's
Criminal Code 5237).

You are incorrect in saying that TÜBİTAK was involved in the appointment of supporters of Turkey's ruling Justice and Development Party to key academic positions. Most of the scientists in TÜBİTAK's senior management were working at the agency for many years before the ruling party took over. The organization has insisted on transparent recruitment procedures since 2006.

Regarding the allegation of Darwin being removed from the cover of TÜBİTAK's popularscience magazine Bilim ve Teknik (Nature 458, 259; 2009), the magazine published a special issue on Darwin in June 2009, as originally scheduled. There was never any censorship, as confirmed by the Ankara Fifth Criminal Court.

Nüket Yetiș TÜBİTAK, Ankara, Turkey.nuket.yetis@tubitak.gov.tr

\section{Microbial sequences} benefit health now

We are still waiting for widespread health-care improvements resulting from sequencing of the human genome (Nature 470, 140; 2011), but microbial genome sequences are already generating important clinical applications.

Hospital laboratory sequencing is set to become an invaluable tool for the delineation, tracking and control of infections such as methicillin-resistant Staphylococcus aureus (MRSA) and Streptococcus pneumoniae (see, for example, S. R. Harris et al. Science 327, 469-474; 2010, and N. J. Croucher et al. Science 331, 430-434; 2011). It will also be crucial for monitoring antibiotic resistance and emerging pathogens such as those responsible for severe acute respiratory syndrome (SARS), $\mathrm{H} 5 \mathrm{~N} 1$ and $\mathrm{H} 1 \mathrm{~N} 1$ influenza.

The use of routine sequencing in diagnostic laboratories will revolutionize our understanding of infectious diseases. By reducing the need for microbiological reference laboratories, there will be fewer delays in delivering information. Sequencing will provide the ultimate source of clinically relevant information on responses to vaccines and microbial drug resistance, for example, as well as useful publichealth data. It will also help to direct research by enabling realtime tracking of pathogens. Edward J. P. Cartwright University of Cambridge, UK. Claudio U. Köser Health Protection Agency, Cambridge; and University of Cambridge, UK. Sharon J. Peacock The Wellcome Trust Sanger Institute; Health Protection Agency, Cambridge; and University of Cambridge, UK. sharon@tropmedres.ac

\section{Career postdocs increase scrap heap}

Jennifer Rohn's solution to the problems of postdoctoral careers does not add up (Nature 471, 7; 2011).

Most fields of science are at a steady state of funding, or worse, so paying for new professional postdocs would require cuts to training postdoc positions. But a career spans 30-40 years, so each career postdoc would replace 6-20 training postdocs. If there were enough professional postdoc positions to make a difference, there would be a huge reduction in the number of training postdocs. The scrap heap would be larger: each rescued professional postdoc would be replaced by several new $\mathrm{PhDs}$ with no chance of finding a postdoc position.

The only other way to avoid a scrap heap would be to restrict the number of people who start $\mathrm{PhDs}$, which raises a host of other complex issues.

Robert Insall Beatson Institute for Cancer Research, Glasgow, UK. r.insall@beatson.gla.ac.uk 